\title{
Thermoplastic Forming of a Hydrophilic Surface with a Nanostructure Array on Zr-Cu-Ni-Al-Y Bulk Metallic Glass
}

\author{
Sirui Cheng ${ }^{1,2}$, Jiang Ma ${ }^{1, *}$, Feng Gong ${ }^{1, *}$ and Jun Shen ${ }^{1}$ \\ 1 College of Mechatronics and Control Engineering, Shenzhen University, Shenzhen 518060, China; \\ chengsr@szu.edu.cn (S.C.); junshen@szu.edu.cn (J.S.) \\ 2 College of Physics and Optoelectronic Engineering, Shenzhen University, Shenzhen 518060, China \\ * Correspondence: majiang@szu.edu.cn (J.M.); gongfeng@szu.edu.cn (F.G.); Tel.: +86-755-26534231 (J.M.)
}

check for updates

Citation: Cheng, S.; Ma, J.; Gong, F.; Shen, J. Thermoplastic Forming of a Hydrophilic Surface with a Nanostructure Array on Zr-Cu-Ni-Al-Y Bulk Metallic Glass. Metals 2021, 11, 1520. https:// doi.org/10.3390/met11101520

Academic Editor: Antonio J. Gámez

Received: 27 August 2021

Accepted: 21 September 2021

Published: 24 September 2021

Publisher's Note: MDPI stays neutral with regard to jurisdictional claims in published maps and institutional affiliations.

Copyright: (C) 2021 by the authors. Licensee MDPI, Basel, Switzerland. This article is an open access article distributed under the terms and conditions of the Creative Commons Attribution (CC BY) license (https:// creativecommons.org/licenses/by/ $4.0 /)$.

\begin{abstract}
The poor thermoplastic formability of reactive Zr-based bulk metallic glass becomes the main limiting factor for replacing the noble-metal-based and Be-rich bulk metallic glasses in nanostructure fabrication. In our work, a $\left(\mathrm{Zr}_{50.7} \mathrm{Cu}_{28} \mathrm{Ni}_{9} \mathrm{Al}_{12.3}\right)_{98.5} \mathrm{Y}_{1.5}$ bulk metallic glass with good thermoplastic formability has been developed by alloying, where $\mathrm{Y}$ addition enlarges the processing window and decreases the viscous resistance of supercooled liquid caused by the high free volume density. The prepared $\mathrm{Zr}-\mathrm{Cu}-\mathrm{Ni}-\mathrm{Al}-\mathrm{Y}$ bulk metallic glass nanostructure retains the amorphous characteristic and generates the complex oxidization products in the surface layer. The enhanced hydrophilicity of the as-embossed surface follows a Wenzel-impregnating wetting regime, and it can be attributed to the large roughness coefficient induced by the capillary effect. This study provides a low-cost and environmentally friendly bulk metallic glass system to manufacture the nanostructure with a broad prospect in the field of electrocatalysis.
\end{abstract}

Keywords: Zr-Cu-Ni-Al-Y bulk metallic glass; nanostructure array; hot embossing microstructure; wettability

\section{Introduction}

Bulk metallic glasses (BMGs) are considered potential catalysts because of their good mechanical properties, outstanding stability in corrosive media and relatively high reaction activity that results from their unique metastable microstructures [1-4]. Thus, BMGs can play an important role in the development of energy conversion and storage technology $[5,6]$. The fabrication of BMG components with nanostructures, which can significantly increase the high specific surface area, has attracted considerable interest in the fields of fuel cells and electrochemistry to improve catalytic performance $[7,8]$. At present, the BMG systems usually utilized in the fabrication of nanostructures and electrocatalysis research primarily consist of Pt-based and Pd-based BMGs because of their outstanding thermoplastic formability and oxidation resistance [9-12]. Some studies on low-cost BMG systems, including Zr-Ti-Cu-Be and Ti-Zr-Be-Fe [13,14], have also been performed to replace noble metal-based BMGs in preparing nanostructures. However, expensive raw materials and mass Be addition, which may cause serious environmental threats, hinder the practical application of the aforementioned BMG systems. Therefore, developing new economical and environmentally friendly BMGs and the corresponding thermoplastic forming (TPF) method is necessary to achieve the fabrication of the BMG nanostructure. To date, few reports are found on hot embossing of reactive BMG (including $\mathrm{Zr}-\mathrm{Cu}-\mathrm{Al}, \mathrm{Zr}-\mathrm{Cu}-\mathrm{Ni}-\mathrm{Al}$ or Zr-Co-Al BMG systems) nanostructure arrays with a characteristic size of less than $1 \mu \mathrm{m}$.

The main challenges in designing the BMG system suitable for nanostructure fabrication are to enlarge the TPF window, decrease the viscous resistance and optimize the interfacial states of supercooled liquid $[15,16]$. Many researchers have pointed out that $Y$ addition can not only improve the thermal stability of Zr-based BMG and decrease the 
viscosity of supercooled liquid but also contribute to the thin oxide layer on the specimen surface [17-19]. Following this strategy, Zr-Cu-Ni-Al-Y BMG systems can meet the requirements concerning the TPF of nanostructures and are expected to become promising candidates as future electrocatalysis materials. In this paper, the high-aspect-ratio nanopillar array on $\left(\mathrm{Zr}_{50.7} \mathrm{Cu}_{28} \mathrm{Ni}_{9} \mathrm{Al}_{12.3}\right)_{98.5} \mathrm{Y}_{1.5}\left(\mathrm{ZrY}_{1.5}\right)$ BMG was prepared under a low-vacuum condition, suggesting that the developed $\mathrm{Zr}$-based BMG with excellent thermoplastic formability can support the need for nanostructure fabrication when reducing the material cost and environmental threat. The phase composition and structural characteristics of the nanopillars, as the main factors determining the catalytic efficiency, were retained after the TPF. In addition, the good wettability of BMG specimens with nanostructure array was obtained, thereby confirming their potential application in the electrocatalytic field.

\section{Materials and Methods}

The alloy ingots with nominal compositions of $\mathrm{Zr}_{50.7} \mathrm{Cu}_{28} \mathrm{Ni}_{.9} \mathrm{Al}_{12.3}\left(\mathrm{ZrY}_{0}\right)$ and $\left(\mathrm{Zr}_{50.7}\right.$ $\left.\mathrm{Cu}_{28} \mathrm{Ni}_{9} \mathrm{Al}_{12.3}\right)_{98.5} \mathrm{Y}_{1.5}\left(\mathrm{ZrY}_{1.5}\right)$ were prepared by arc melting high-purity constituents (>99.9 wt.\%) under Ti-gettered high-purity argon atmosphere. All ingots were melted and flipped at least four times to ensure compositional homogeneity and then cast into a copper mold to obtain BMG rods with diameters of $5 \mathrm{~mm}$, as shown in Figure 1a. The $1 \mathrm{~mm}$ thick specimens cut from these BMG rods were polished and stacked on the top of the anodized aluminum oxide (AAO) templates with 200-300 nm diameter pores. Subsequently, the preforms were placed into the mold cavity and pressed under a constant load of $10 \mathrm{kN}$. The temperature path of the TPF was set at $20 \mathrm{~K} / \mathrm{min}$ under a low-vacuum condition (approximately 100-150 Pa) until the temperature reached the set value; see Figure $1 \mathrm{~b}$. Afterward, the as-embossed preforms were moved into $3 \mathrm{~mol} / \mathrm{L} \mathrm{KOH}$ solution at $80{ }^{\circ} \mathrm{C}$ to dissolve the AAO templates, as shown in Figure 1c.

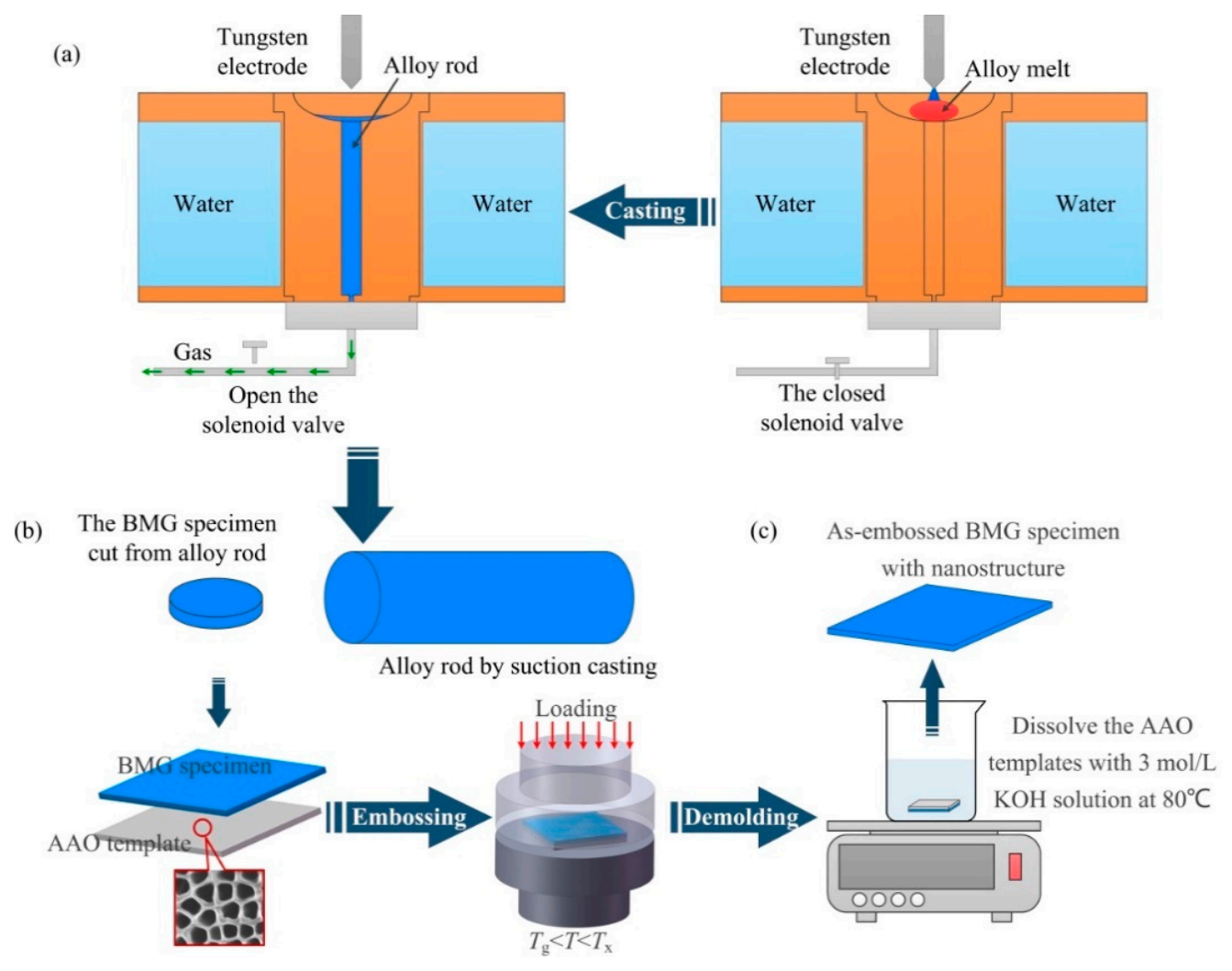

Figure 1. Preparation process of BMG nanostructure: (a) prepare the Zr-based BMG rods by arc melting and copper mold suction casting; (b) hot embossing of nanostructure on the surface of BMG specimens; (c) demolding process of the as-embossed BMG specimens. 
The amorphous nature of BMG specimens before and after TPF was tested using X-ray diffraction (XRD, Rigaku MiniFlex600, Tokyo, Japan) with $\mathrm{Cu}-\mathrm{K} \alpha$ radiation. The thermodynamic properties of these two BMGs, such as characteristic temperature and relaxation enthalpy, were studied by differential scanning calorimetry (DSC, Netzsch 404 F3, NETZSCH-Gerätebau GmbH, Selb, Germany) at continuous heating rates of $10 \mathrm{~K} / \mathrm{min}$ under a flow of high purity argon. Their viscosities as a function of temperature in the supercooled liquid region were measured by using a thermal-mechanical analyzer (TMA, Netzsch Q400EM, NETZSCH-Gerätebau GmbH, Selb, Germany) with a heating rate of $10 \mathrm{~K} / \mathrm{min}$ and a static force of $1.2 \mathrm{~N}$. The oxidation experiments were performed by a thermal gravimetric analyzer (TGA, Mettler-Toledo DSC3+, Columbus, OH, USA) in dry air (>99.99 vol.\% pure). The surface morphology of the as-embossed specimen was observed by field-emission scanning electron microscopy (FEI SEM, Quanta450FEG, Hillsboro, OR, USA). Furthermore, the microstructure of the nanopillar was examined using a transmission electron microscope (TEM, Tecnai F30, FEI, Hillsboro, OR, USA). The water contact angle measured via an optical-contact angle-measuring device based on video (DSA 100S, KRÜSS GmbH, Hamburg, Germany) was used to estimate the wettability of the smooth and as-embossed $\mathrm{ZrY}_{1.5}$ BMG surfaces. The test was conducted in an atmospheric environment with a $2 \mu \mathrm{L}$ droplet of distilled deionized water at room temperature.

\section{Results and Discussion}

The XRD pattern of the $\mathrm{ZrY}_{0}$ BMG shows a slight diffraction peak superimposed with the diffuse halo, revealing the crystalline phases ( $\mathrm{ZrCu}$ phase) in the amorphous matrix, as shown by the black curve in Figure 2. Different from $\mathrm{ZrY}_{0} \mathrm{BMG}$, no other diffraction peaks of crystalline phases can be observed on the XRD pattern of as-cast $\mathrm{ZrY}_{1.5}$ BMG, indicating a fully amorphous structure and good glass-forming ability (see the gray curve in Figure 2). In general, BMG will entirely change to supercooled liquid and obtain the relatively loose atomic arrangement at the temperature corresponding to the end of glass transition $\left(T_{\text {end }}\right)$, causing the activated atoms to easily jump into the adjacent free volume. Therefore, the viscous flow of BMG supercooled liquid will start roughly at $T_{\text {end }}$ [20], and the TPF window can be defined by the temperature from $T_{\text {end }}$ to $T_{\mathrm{x}}$. From the non-isothermal DSC curves in Figure $3 \mathrm{a}, \mathrm{ZrY}_{1.5} \mathrm{BMG}$ represents a low $T_{\text {end }}$ and wide TPF region $\Delta T_{\mathrm{TPF}}=T_{\mathrm{x}}-T_{\text {end }}(56 \mathrm{~K})$, which can maintain the disordered structural characteristics after hot exposure to delay the fluidity drop of $\mathrm{ZrY}_{1.5}$ BMG caused by crystallization during thermoplastic forming. In addition, the enthalpy value by the structural relaxation of $\mathrm{ZrY}_{1.5}$ BMG $\left(\Delta H_{\mathrm{ZrY} 1.5}\right)$ is $1.368 \mathrm{~J} / \mathrm{g}, 43 \%$ larger than that of $\mathrm{ZrY}_{0} \mathrm{BMG}\left(\Delta H_{\mathrm{ZrY} 0}=0.957 \mathrm{~J} / \mathrm{g}\right)$, revealing a high free volume content (see Figure 3b) [21-24]. The low atomic stacking density is closely related to the low energy dissipation during creep flow, thereby reducing the viscous resistance of BMG-supercooled liquid. This finding is proven by the TMA scanning curve of $\mathrm{ZrY}_{1.5}$ BMG in Figure 4a. By numerically integrating the inverse of the viscosity curves [25], the variations of thermoplastic formability are intuitively reflected in Figure $4 \mathrm{~b}$. Based on these reasons mentioned above, the relatively good thermoplastic formability of $\mathrm{ZrY}_{1.5} \mathrm{BMG}$ in the supercooled liquid region can be attributed to the optimized thermodynamic and kinetic properties induced by $\mathrm{Y}$ addition $[26,27]$.

The oxidation data obtained from the two as-cast BMGs over the TPF region are shown in Figure 5 and insert. The mass-gain rate for the $\mathrm{ZrY}_{1.5} \mathrm{BMG}$ is significantly lower than that for the $\mathrm{ZrY}_{0} \mathrm{BMG}$ in the temperature range of interest, similar to that reported in the previous study about the oxidation behavior of Zr-Cu-Ni-Al-Y BMG systems. Lu et al. [19] pointed out that the $\mathrm{Y}$ element can preferentially migrate from the matrix to the surface and suppress the diffusivity of other elements, resulting in a thinner oxide layer so as to decrease the surface tension of $\mathrm{Zr}-\mathrm{Cu}-\mathrm{Ni}-\mathrm{Al}-\mathrm{Y}$ supercooled liquid. The improved oxidation resistance of $\mathrm{ZrY}_{1.5}$ BMG reduces the pressure drop of supercooled liquid when flowing in the nanopores. Therefore, the nanostructure can be formed under pressure lower than the fracture strength of the AAO template. 


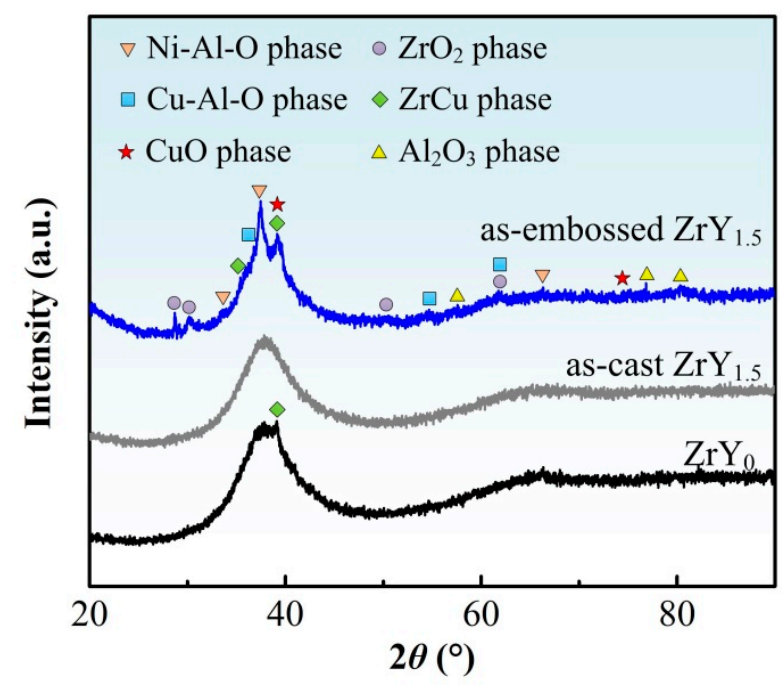

Figure 2. XRD patterns of the two as-cast BMGs and the as-embossed $\mathrm{ZrY}_{1.5}$ surface.
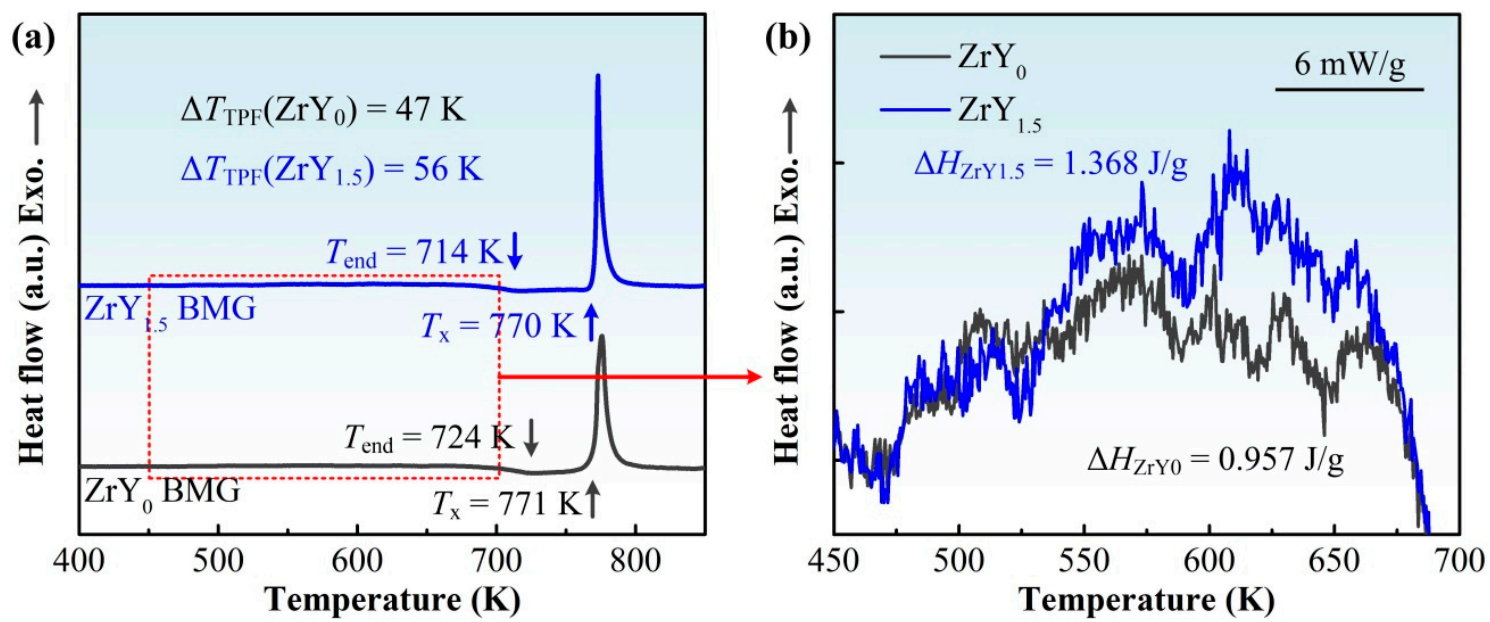

Figure 3. Thermodynamic properties of the as-cast $\mathrm{ZrY}_{0}$ BMG and $\mathrm{ZrY}_{1.5}$ BMG: (a) DSC curves of the two BMGs; (b) the structural relaxation below the glass transition temperature.
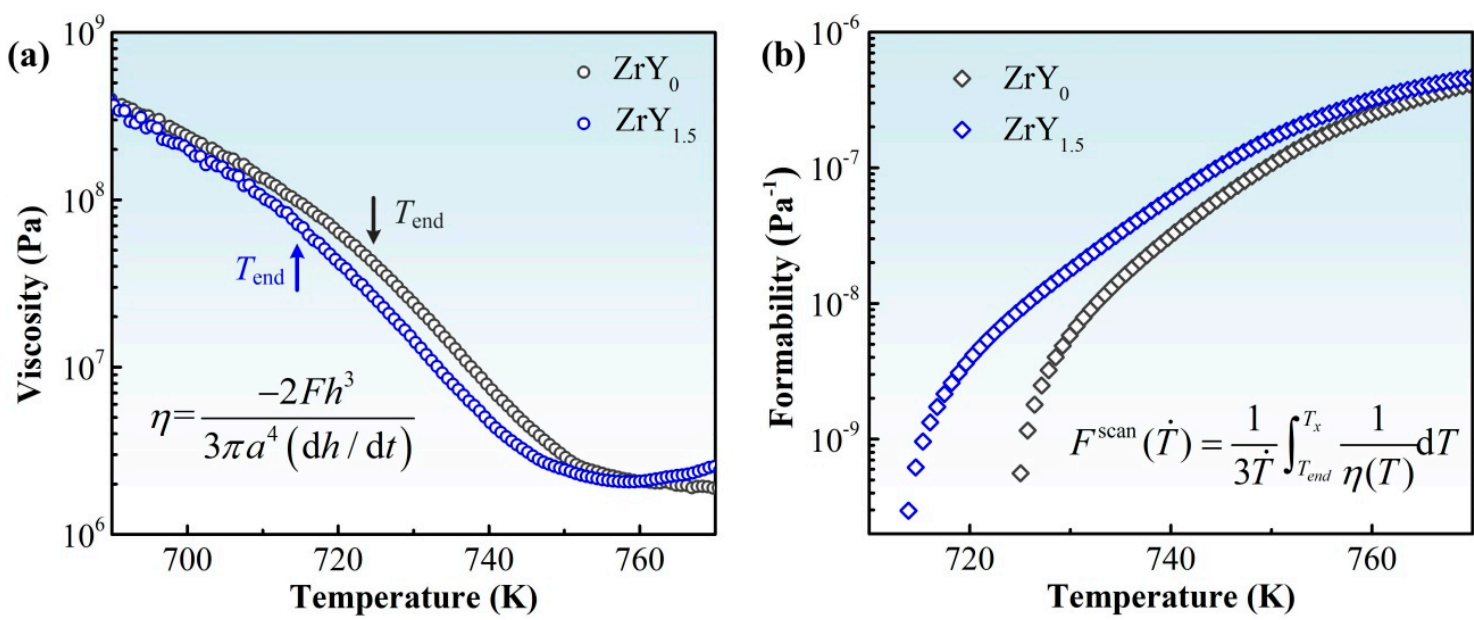

Figure 4. Kinetic properties of the as-cast $\mathrm{ZrY}_{0}$ BMG and $\mathrm{ZrY}_{1.5}$ BMG: (a) the TMA continuous scanning curves of the two BMGs; (b) the quantitative thermoplastic formability. 


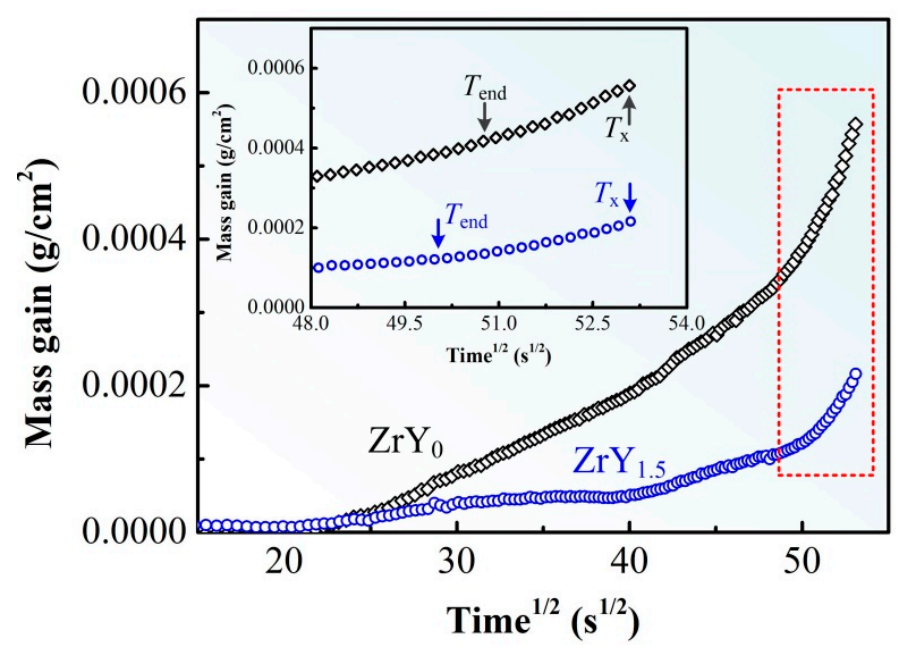

Figure 5. Parabolic plots of the mass-gain data for the $\mathrm{ZrY}_{0} \mathrm{BMG}$ and $\mathrm{ZrY} \mathrm{Y}_{1.5} \mathrm{BMG}$ under the heating rate of $10 \mathrm{~K} / \mathrm{min}$.

The morphology of the $300 \mathrm{~nm}$ nanostructure array on the $\mathrm{ZrY}_{1.5}$ BMG surface after non-isothermal embossing is shown in Figure 6. The lengths of these obtained nanopillars are measured to be over $1 \mu \mathrm{m}$, and their aspect ratios exceed 3. The characteristic sizes of the gaps among these nanopillars are about $50 \mathrm{~nm}$, as shown in the insert. The EDS result shows that the content of oxygen is over $60 \%$, indicating an oxygen-rich layer formed on the surface of the nanopillar (Table 1). From the XRD pattern of the as-embossed specimen, some diffraction peaks are superimposed on the amorphous halo, reflecting the complex oxidation products in the surface layer of these nanopillars, including $\mathrm{Ni}$ $\mathrm{Al}-\mathrm{O}, \mathrm{Cu}-\mathrm{Al}-\mathrm{O}, \mathrm{ZrO}_{2}, \mathrm{CuO}$ and $\mathrm{Al}_{2} \mathrm{O}_{3}$ phases (see the blue curve in Figure 2). The rigid oxygen-rich layer will prohibit the viscous flow of supercooled liquid, causing the original $\mathrm{Zr}-\mathrm{Cu}-\mathrm{Ni}-\mathrm{Al} \mathrm{BMG}$ systems to be unsuitable for nanostructure fabrication under ambient conditions [28]. However, the oxide layer should not be regarded as just a negative factor affecting thermoplastic formability. In many cases, the tiny oxidation products, as effective sites, boost the various electrocatalytic reactions [29-31]. Thus, the nanostructure array can be endowed with different functions by surface modification or surface coating [6].

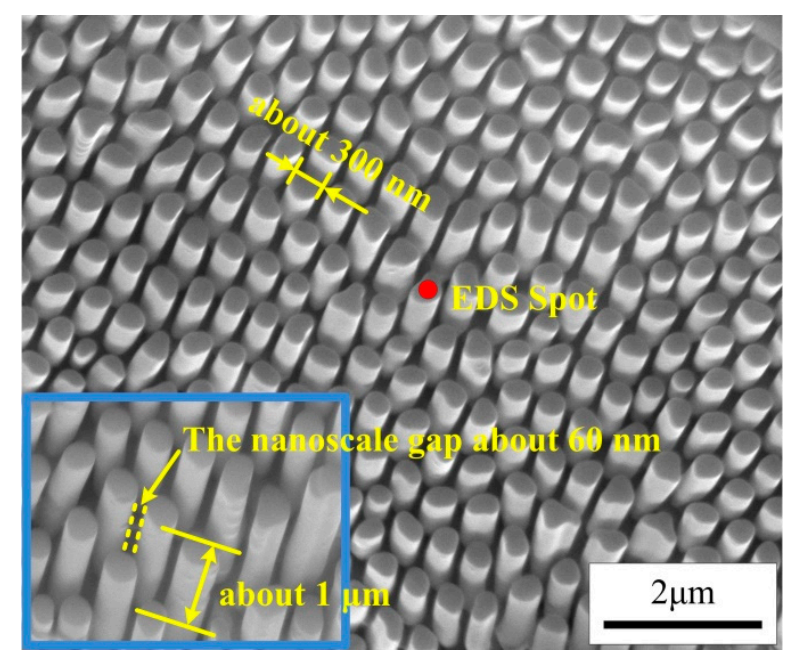

Figure 6. Morphology of the as-embossed nanostructure array with the characteristic size of $300 \mathrm{~nm}$. 
Table 1. EDS results of the nanopillar surface.

\begin{tabular}{ccc}
\hline Element & Weight wt. $\%$ & Atomic at. $\%$ \\
\hline $\mathrm{Zr}$ & 26.71 & 9.09 \\
$\mathrm{Cu}$ & 19.18 & 9.37 \\
$\mathrm{Ni}$ & 5.16 & 2.73 \\
$\mathrm{Al}$ & 11.82 & 13.60 \\
$\mathrm{Y}$ & 4.27 & 1.49 \\
$\mathrm{O}$ & 32.84 & 63.72 \\
\hline
\end{tabular}

For investigating the structural state of the as-embossed specimen, the high-angle annular dark-field image of a single nanopillar is shown in Figure 7a. As shown in the figure, the diameter of the nanopillar is measured to be $390 \mathrm{~nm}$, which is consistent with the SEM results. Considering the aspect ratio of a single nanopillar is over 3, the prepared nanostructure array should possess a huge specific surface area. Figure $7 \mathrm{~b}$ shows two distinct regions, including a nanopillar matrix and surface layer, where the nanopillar matrix still exhibits a fully amorphous structure, as indicated by their corresponding selected area electron diffraction (SAED) patterns (insets of Figure 7b), whereas the surface layer is partially crystallized. Although a small number of oxygen atoms in the ambient dramatically promote the structural ordering of reactive Zr-based BMGs [32,33], the short TPF time (less than $180 \mathrm{~s}$ ) can restrain the long-distance diffusion of oxygen atoms. Combined with the fact that the micro defects on the AAO templates can be the nucleation site of the crystalline phase, crystallization is only found on the surface and not in the core of the nanopillar. Subsequently, these crystalline phases would be crushed by the BMG supercooled liquid with a Newtonian flow characteristic, thereby forming the discontinuous ordered structures in the surface layer [34,35]. Figure 7c shows the EDXS mapping results of the nanopillar, in which the main component elements $(\mathrm{Zr}, \mathrm{Cu}, \mathrm{Ni}, \mathrm{Al}, \mathrm{Y}$ and solute $\mathrm{O})$ are dispersed uniformly along the nanopillar. The distribution states of these component elements eliminate the possibility of severe crystallization in the surface layer. That means the as-embossing $\mathrm{Zr}-\mathrm{Cu}-\mathrm{Ni}-\mathrm{Al}-\mathrm{Y}$ BMG can maintain the mass-free volume in those nanopillars to ensure the specific functions depending on the amorphous characteristic, despite the nanoscale-ordered structure generation in the TPF stage.

The water contact angle tests were performed on the $\mathrm{ZrY}_{1.5}$ BMG specimens before and after non-isothermal embossing to study the effects of the nanostructure array on wettability. Figure 8a shows the results for the $\mathrm{ZrY}_{1.5}$ BMG without hot embossing, which is $87^{\circ}$ and similar to the values published for other Zr-based BMGs [36], corresponding to an indistinct hydrophilic property of the smooth surface. The water contact angle of the as-embossed surface decreases to $61^{\circ}$, which is $30 \%$ lower than that of the smooth surface, as depicted in Figure $8 \mathrm{~b}$. Then, the water contact angles on the smooth and as-embossed surface slightly decrease with time (Figure 8c). In this case, a positive effect of the prepared nanostructure array on the wettability can be confirmed. According to conventional wisdom, the preparation of a microstructure on the solid surface is an effective method to improve hydrophobicity [37] because the trapped air prevents the water from wetting the gaps, which changes the apparent property of the macroscopic interface. However, contrary to this common notion, the nanostructure array endows hydrophilic $\mathrm{ZrY}_{1.5}$ BMG with better hydrophilicity. The nanostructure array can decrease the water contact angle of the BMG specimen, probably because the significant capillary effect drives the water to flow into those nanoscale gaps, thereby avoiding the air film between the BMG matrix and water droplet, which indicates that the actual surface of the nanostructure array can be fully wetted by the water (diagrammatic sketch in Figure 8d). This solid-liquid interface is in accordance with a typical state of the Wenzel-impregnating wetting regime [38], which decreases the water contact angle of the as-embossed surface. 

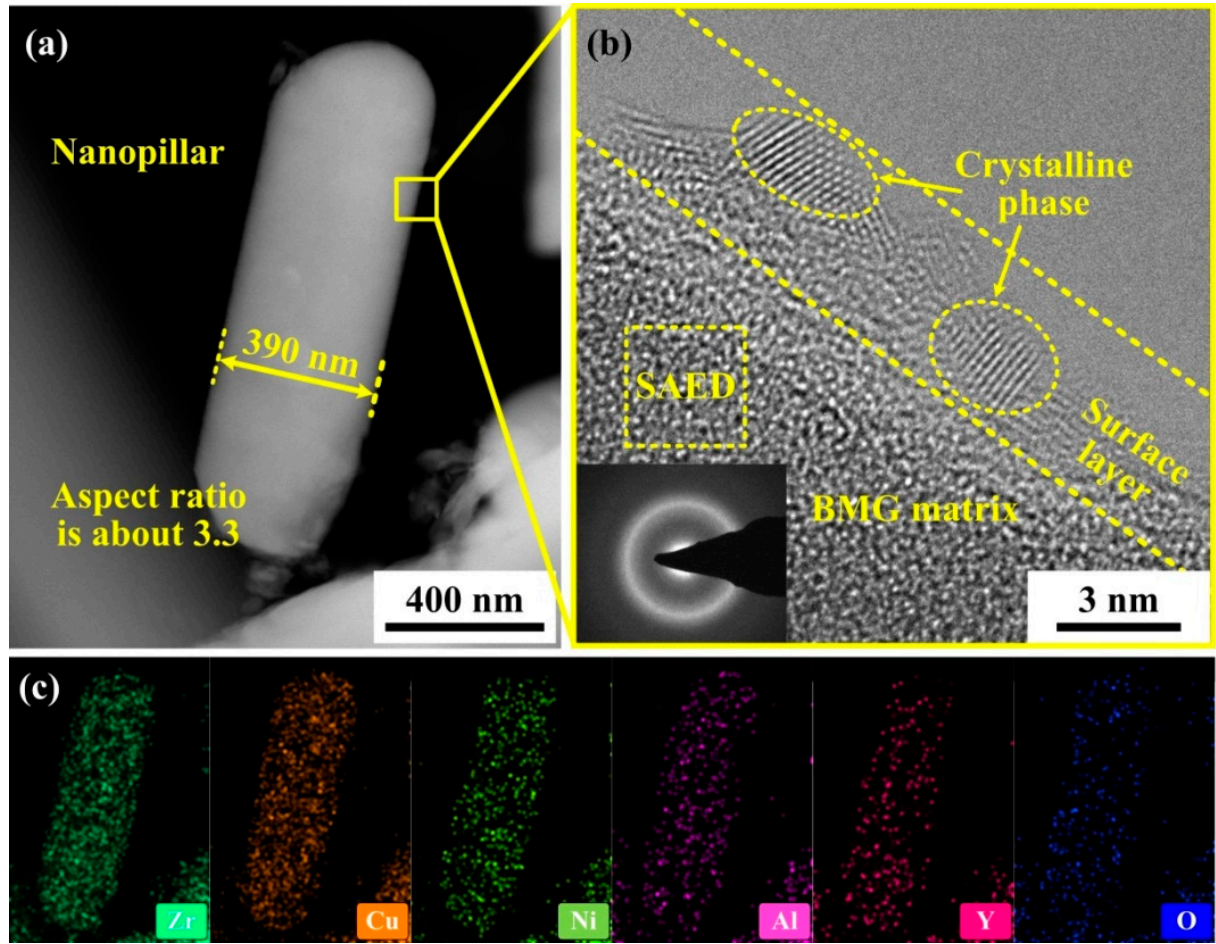

Figure 7. (a) Morphology of a single nanopillar with a diameter of $390 \mathrm{~nm}$ under TEM. (b) HRTEM image of nanopillar with two typical regions at the boundary; the insets are the selected area electron diffraction (SAED) patterns corresponding to the nanopillar matrix. (c) Energy spectrum analysis of a single nanopillar under TEM.
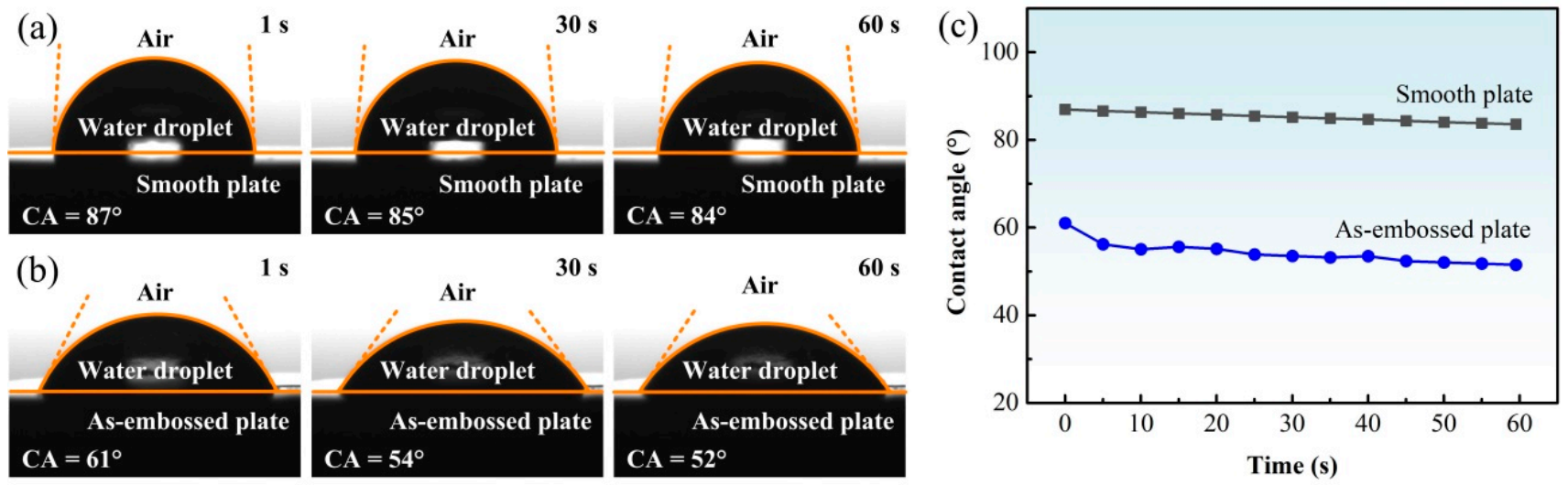

(d)

Hydrophilic materials

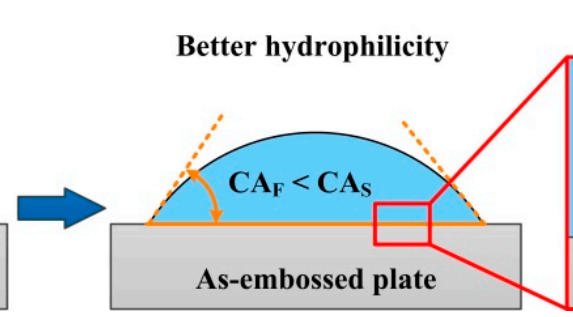

Wenzel impregnating wetting regime

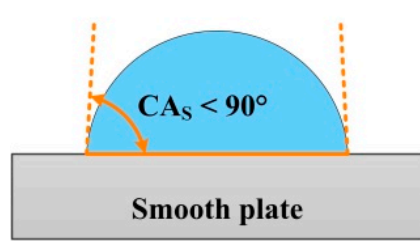

Figure 8. (a) Contact angle on the smooth $\mathrm{ZrY}_{1.5}$ BMG plate. (b) Contact angle on the $\mathrm{ZrY}_{1.5}$ BMG plate with nanostructure array. (c) The variations of water contact angle on the BMG surface before and after non-isothermal embossing. (d) Diagrammatic sketch of a water droplet in contact with the $\mathrm{ZrY}_{1.5}$ BMG plate with nanostructure (Wenzel's model). 
Based on Wenzel's model, $\cos \theta^{*}=r \cos \theta$ (where $\theta$ is the contact angle on the ideally smooth surface, $\theta^{*}$ is the apparent contact angle in a stable equilibrium state and $r$ is the roughness coefficient defined as the proportion of the actual area $S_{\mathrm{A}}$ and apparent surface $S)$, the contact angle of the as-embossed surface is controlled by the $r$ value. Taking a single nanopillar as an example (see Figure 9a), the modified Wenzel's model related to the geometric parameter of the BMG nanostructure array can be written as Equation (1) by substituting $S_{\mathrm{A}}$ and $S$ in Figure 9a:

$$
\theta^{*}=\arccos \left[\left(1+\frac{\alpha \pi}{\beta^{2}}\right) \times \cos \theta\right]
$$

where $\alpha$ denotes the aspect ratio of a single nanopillar and $\beta$ denotes the spacing proportion factor. The calculation results reveal that the water contact angle monotonously decreases with the increasing aspect ratio of nanopillar. The high aspect ratio $\alpha$, leading to a large $r$-value, can increase the difference between $\theta$ and $\theta^{*}$ so that the as-embossed surface obtains good wettability. Besides, Equation (1) also indicates the size dependence of the apparent contact angle. The large gaps between nanopillars may weaken the positive effect of capillarity on the liquid-solid interface roughness coefficient, which is unfavorable for the hydrophilicity improvement of the $\mathrm{ZrY}_{1.5}$ BMG surface with nanostructure array by the Wenzel-impregnating wetting regime [39-41]. This inference is in agreement with the mathematical relationship between $\beta$ and $\theta^{*}$ for $\mathrm{ZrY}_{1.5}$ BMG (see the black curve and red points in Figure $9 b$ ). The small gap significantly decreases the water contact angle of the as-embossed surface, particularly when the spacing proportion factor is less than 1.25, as marked in the shaded box. These theoretical analyses and experimental results can quantify the correlation between the geometric parameters of the BMG nanostructure array and hydrophilicity and guide the design and fabrication of new functional components.
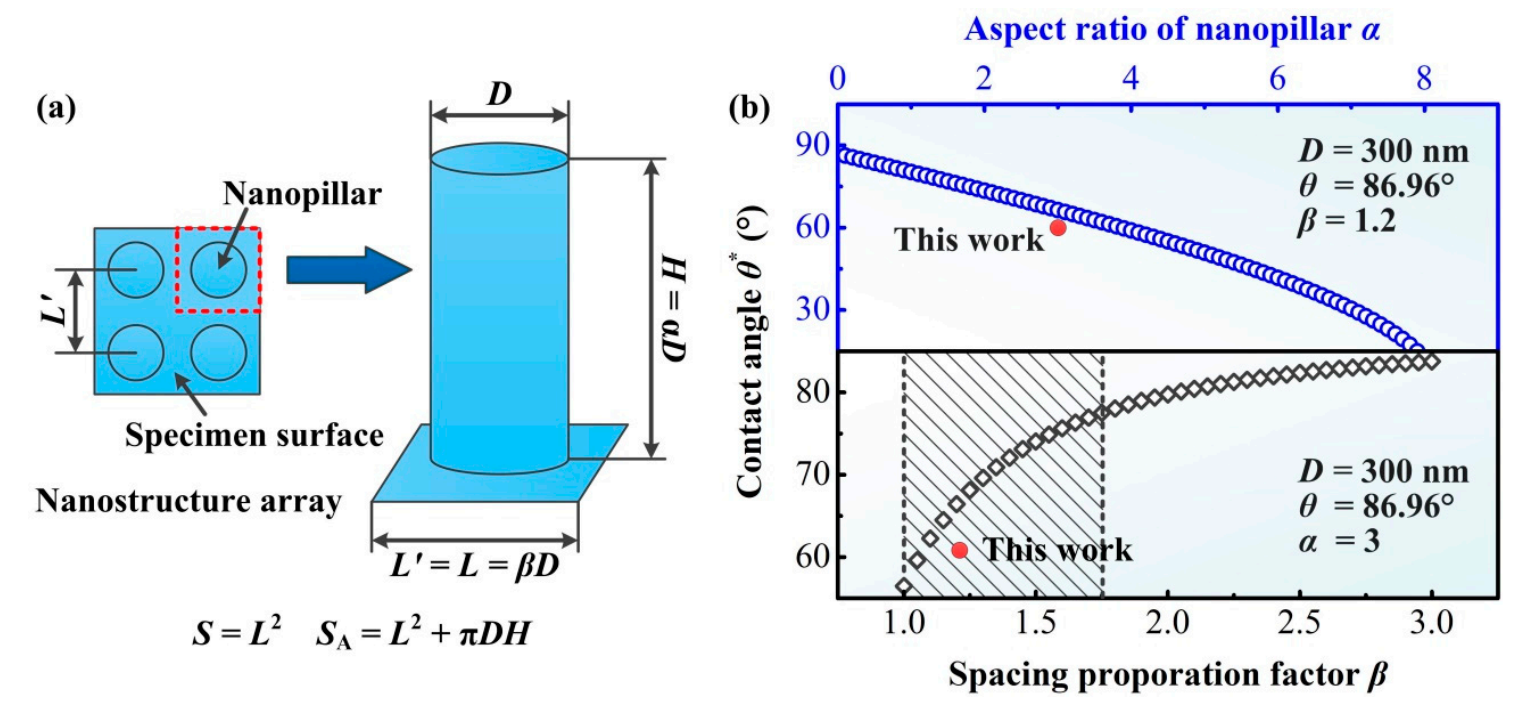

Figure 9. (a) Geometric parameter of BMG nanostructure array. (b) The apparent contact angle of the as-embossed $\mathrm{ZrY}_{1.5}$ BMG surface based on Wenzel's model.

\section{Conclusions}

The nanostructure array was successfully fabricated on the surface of $\mathrm{ZrY}_{1.5}$ BMG by non-isothermal embossing. The aspect ratio of these prepared $300 \mathrm{~nm}$ pillars was more than 3. The relatively complete amorphous characteristic of the as-embossed specimen was retained, and the oxygen-rich layer, including $\mathrm{Ni}-\mathrm{Al}-\mathrm{O}, \mathrm{Cu}-\mathrm{Al}-\mathrm{O}, \mathrm{ZrO}, \mathrm{CuO}$ and $\mathrm{Al}_{2} \mathrm{O}_{3}$ phases, was formed on the surface of nanopillar after TPF. The wettability of the as-embossed surface follows Wenzel's model under the capillary effect, which decreased the contact angle from $87^{\circ}$ to $61^{\circ}$, thus enhancing the hydrophilicity of $\mathrm{ZrY}_{1.5} \mathrm{BMG}$ with a 
nanostructure array. The present work has developed an environmentally friendly nonnoble-metal-based BMG to prepare the nanostructure and prove the application potential of the multifunctional surface with a nanostructure array.

Author Contributions: Conceptualization, S.C. and J.S.; methodology, S.C.; validation, S.C., J.M. and F.G.; formal analysis, J.S.; investigation, S.C.; resources, F.G.; data curation, S.C.; writing-original draft preparation, S.C.; writing-review and editing, J.S.; visualization, J.M.; supervision, J.S. and J.M.; project administration, J.S. and J.M.; funding acquisition, J.S. All authors have read and agreed to the published version of the manuscript.

Funding: This work is supported by the National Key Research and Development Program of China (Grant No. 2018YFA0703605) and the China National Natural Science Foundation (No. 52071217).

Institutional Review Board Statement: Not applicable.

Informed Consent Statement: Not applicable.

Data Availability Statement: All data generated or analyzed during this study are included in this published article.

Conflicts of Interest: The authors declare that they have no known competing financial interest or personal relationships that could have appeared to influence the work reported in this paper.

\section{References}

1. Zhang, F.; Wu, J.; Jiang, W.; Hu, Q.Z.; Zhang, B. New and efficient electrocatalyst for hydrogen production from water splitting: Inexpensive, robust metallic glassy ribbons based on iron and cobalt. ACS Appl. Mater. Interfaces 2017, 9, 31340. [CrossRef]

2. Hu, Y.C.; Sun, C.X.; Sun, C.W. Functional applications of metallic glasses in electrocatalysis. Chem CatChem 2019, 11, 2401-2414. [CrossRef]

3. Ghidelli, M.; Orekhov, A.; Bassi, A.L.; Terraneo, G.; Djemia, P.; Abadias, G.; Nord, M.; Béché, A.; Gauquelin, N.; Verbeeck, J.; et al. Novel class of nanostructured metallic glass films with superior and tunable mechanical properties. Acta Mater. 2021, $213,116955$. [CrossRef]

4. Sarac, B.; Spieckermann, F.; Rezvan, A.; Gammer, C.; Krämer, L.; Kim, J.T.; Keckes, J.; Pippan, J.; Eckert, J. Annealing-assisted high-pressure torsion in $\mathrm{Zr}_{55} \mathrm{Cu}_{30} \mathrm{Al}_{10} \mathrm{Ni}_{5}$ metallic glass. J. Alloys Compd. 2019, 784, 1323-1333. [CrossRef]

5. Carmo, M.; Sekol, R.C.; Ding, S.Y.; Kumar, G.; Schroers, J.; Taylor, A.D. Bulk metallic glass nanowire architecture for electrochemical applications. ACS Nano 2011, 5, 2979-2983. [CrossRef] [PubMed]

6. Doubek, G.; Sekola, R.C.; Li, J.Y.; Ryu, W.H.; Gittleson, F.S.; Nejati, S.; Moy, E.; Reid, C.; Carmo, M.; Linardi, M.; et al. Guided evolution of bulk metallic glass nanostructures: A platform for designing 3D electrocatalytic surfaces. Adv. Mater. 2016, 28, 1940-1949. [CrossRef]

7. Sekol, R.C.; Kumar, G.; Carmo, M.; Gittleson, F.; Hardesty-Dyck, N.; Mukherjee, S.; Schroers, J.; Taylor, A.D. Bulk metallic glass micro fuel cell. Small 2013, 9, 2081-2085. [CrossRef] [PubMed]

8. Kumar, G.; Blawzdziewicz, J.; Schroers, J. Controllable nanoimprinting of metallic glasses: Effect of pressure and interfacial properties. Nanotechnology 2013, 24, 105301. [CrossRef] [PubMed]

9. Liu, X.; Shao, Y.; Feng, J.; Chen, N.; Yao, K.F. Large-area and uniform amorphous metallic nanowire arrays prepared by die nanoimprinting. J. Alloys Compd. 2014, 605, 7-11. [CrossRef]

10. Lim, K.R.; Kim, C.E.; Yun, Y.S.; Kim, W.T.; Soon, A.; Kim, D.H. Remarkably stable amorphous metal oxide grown on Zr-Cu-Be metallic glass. Sci. Rep. 2015, 5, 18196. [CrossRef]

11. Lim, K.R.; Park, J.M.; Kim, S.J.; Lee, E.S.; Kim, W.T.; Gebert, A.; Eckert, J.; Kim, D.H. Enhancement of oxidation resistance of the supercooled liquid in $\mathrm{Cu}-\mathrm{Zr}$-based metallic glass by forming an amorphous oxide layer with high thermal stability. Corros. Sci. 2013, 66, 1-4. [CrossRef]

12. Hasan, M.; Warzywoda, J.; Kumar, G. Decoupling the effects of surface texture and chemistry on the wetting of metallic glasses. Appl. Surf. Sci. 2018, 447, 355-362. [CrossRef]

13. Liu, Z;; Schroers, J. General nanomoulding with bulk metallic glasses. Nanotechnology 2015, 26, 145301. [CrossRef]

14. Gong, P.; Kou, H.C.; Wang, S.B.; Deng, L.; Wang, X.Y.; Jin, J.S. Research on thermoplastic formability and nanomoulding mechanism of lightweight Ti-based bulk metallic glasses. J. Alloys Compd. 2019, 801, 267-276. [CrossRef]

15. Hasan, M.; Kumar, G. High-throughput drawing and testing of metallic glass nanostructures. Nanoscale 2017, 9, 3261-3268. [CrossRef]

16. Gong, P.; Wang, S.B.; Liu, Z.; Chen, W.; Li, N.; Wang, X.Y.; Yao, K.F. Lightweight Ti-based bulk metallic glasses with superior thermoplastic formability. Intermetallics 2018, 98, 54-59. [CrossRef]

17. Li, B.; Li, Y.H.; Yang, K.; Li, J.S.; Fan, X.H. Effect of yttrium addition on the non-isothermal crystallization kinetics and fragility of Cu-Zr-Al bulk metallic glass. Thermochim. Acta 2016, 642, 105-110. 
18. Lu, S.D.; Sun, S.C.; Li, K.H.; Li, H.Y.; Huang, X.X.; Tu, G.F. The effect of Y addition on the crystallization behaviors of Zr-Cu-Ni-Al bulk metallic glasses. J. Alloys Compd. 2019, 799, 501-512. [CrossRef]

19. Lu, S.D.; Sun, S.C.; Tu, G.F.; Huang, X.X.; Li, K.H. The effect of yttrium addition on the air oxidation behavior of Zr-Cu-Ni-Al bulk metallic glasses at $400-500{ }^{\circ}$ C. Corros. Sci. 2018, 137, 53-61. [CrossRef]

20. Bochtler, B.; Stolpe, M.; Reiplinger, B.; Busch, R. Consolidation of amorphous powder by thermoplastic forming and subsequent mechanical testing. Mater. Des. 2018, 140, 188-195. [CrossRef]

21. Stolpe, M.; Kruzic, J.J.; Busch, R. Evolution of shear bands, free volume and hardness during cold rolling of a Zr-based bulk metallic glass. Acta Mater. 2014, 64, 231-240. [CrossRef]

22. Cao, Q.P.; Li, J.F.; Zhou, Y.H.; Jiang, J.Z. Microstructure and microhardness evolutions of $\mathrm{Cu}_{47.5} \mathrm{Zr}_{47.5} \mathrm{Al}_{5}$ bulk metallic glass processed by rolling. Scr. Mater. 2008, 59, 673-676. [CrossRef]

23. Cao, Q.P.; Li, J.F.; Zhou, Y.H.; Horsewell, A.; Jiang, J.Z. Free-volume evolution and its temperature dependence during rolling of $\mathrm{Cu}_{60} \mathrm{Zr}_{20} \mathrm{Ti}_{20}$ bulk metallic glass. Appl. Phys. Lett. 2005, 87, 101901. [CrossRef]

24. Ghidelli, M.; Gravier, S.; Blandin, J.J.; Pardoen, T.; Jean-Pierre Raskin, J.P.; Mompiou, F. Compositional-induced structural change in $\mathrm{Zr}_{x} \mathrm{Ni}_{100-x}$ thin film metallic glasses. J. Alloys Compd. 2014, 615, S348-S351. [CrossRef]

25. Bochtler, B.; Kruse, O.; Busch, R. Thermoplastic forming of amorphous metals. J. Phys. Condens. Matter 2020, $32,244002$. [CrossRef] [PubMed]

26. Yan, M.; Zou, J.; Shen, J. Effect of over-doped yttrium on the microstructure, mechanical properties and thermal properties of a Zr-based metallic glass. Acta Mater. 2006, 54, 3627-3635. [CrossRef]

27. Li, Y.; Li, R.; Pang, S.J.; Chen, B.Q.; Georgarakis, K.; Moulecet, A.L.; Vaughan, G.; Zhang, T.; Yavari, A.R. Investigation of viscosity and crystallization in supercooled-liquid region of Zr-based glassy alloys. J. Non-Cryst. Solids 2012, 358, 150-154. [CrossRef]

28. Liu, L.C.; Hasan, M.; Kumar, G. Metallic glass nanostructures: Fabrication, properties, and applications. Nanoscale 2014, 6, 2027-2036. [CrossRef]

29. Sun, H.H.; Ma, Z.; Qiu, Y.F.; Liu, H.; Gao, G.G. Ni@NiO nanowires on nickel foam prepared via "acid hungry" strategy: High supercapacitor performance and robust electrocatalysts for water splitting reaction. Small 2018, 14, 1800249. [CrossRef]

30. Xie, Y.L.; Yang, S.Y.; Mao, Z.M.; Li, P.; Zhao, C.L.; Cohick, Z.; Huang, P.H.; Huang, T.J. In situ fabrication of 3D Ag@ZnO nanostructures for micro fluidic surface-enhanced Raman scattering systems. ACS Nano 2014, 8, 12175-12184. [CrossRef]

31. Li, Z.Y.; Yadav, R.M.; Sun, L.P.; Zhang, T.Y.; Zhang, J.F.; Ajayan, P.M.; Wu, J.J. CuO/ZnO/C electrocatalysts for $\mathrm{CO}_{2}$-to-C ${ }^{2+}$ products conversion with high yield: On the effect of geometric structure and composition. Appl. Catal. A Gen. 2020, 606, 117829. [CrossRef]

32. Zhou, W.H.; Meng, Y.H.; Duan, F.H.; Huang, W.; Yao, J.H.; Pan, J.; Wang, Y.X.; Li, Y. The effect of oxygen on phase formation in an industrial Zr based bulk metallic glass. Intermetallics 2021, 129, 107055. [CrossRef]

33. Cole, K.M.; Kirk, D.W.; Singh, C.V.; Thorpe, S.J. Role of niobium and oxygen concentration on glass forming ability and crystallization behavior of $\mathrm{Zr}-\mathrm{Ni}-\mathrm{Al}-\mathrm{Cu}-\mathrm{Nb}$ bulk metallic glasses with low copper concentration. J. Non-Cryst. Solids 2016, 445-446, 88-94. [CrossRef]

34. Cheng, S.R.; Zhu, J.H.; Shen, J.; Wei, X.S. Effects of yttrium addition on the thermoplastic formability of Zr-Cu-Ni-Al amorphous alloy under non-isothermal condition. J. Alloys Compd. 2021, 872, 159684. [CrossRef]

35. Wang, C.J.; Cheng, S.R.; Ma, M.Z.; Shan, D.B.; Guo, B. Filling kinetics of Zr-based amorphous supercooled liquid in micro filling process with longer unsteady flow. J. Mater. Process. Technol. 2019, 274, 116265. [CrossRef]

36. Comby-Dassonneville, S.; Venot, T.; Borroto, A.; Longin, E.; Loughian, C.; Ovanessian, B.; Leroy, M.A.; Pierson, J.F.; Steyer, P. ZrCuAg Thin-Film Metallic Glasses: Toward Biostatic Durable Advanced Surfaces. ACS Appl. Mater. Interfaces 2021, 13, 17062-17074. [CrossRef]

37. Xu, J.; Su, Q.; Shan, D.B.; Guo, B. Sustainable micro-manufacturing of superhydrophobic surface on ultrafine-grained pure aluminum substrate combining micro-embossing and surface modification. J. Clean. Prod. 2019, 232, 705-712. [CrossRef]

38. Wenzel, R.N. Resistance of solid surfaces to wetting by water. Ind. Eng. Chem. 1936, 28, 988-994. [CrossRef]

39. Zhang, Y.L.; Chen, Q.D.; Jin, Z.; Kim, E.; Sum, H.B. Biomimetic graphene films and their properties. Nanoscale 2012, 4, 4858-4869. [CrossRef]

40. Feng, L.; Zhang, Y.N.; Cao, Y.Z.; Ye, X.X.; Jiang, L. The effect of surface microstructures and surface compositions on the wettabilities of flower petals. Soft Matter 2011, 7, 2977-2980. [CrossRef]

41. Cassie, A.B.D.; Baxter, S. Wettability of porous surfaces. Trans. Faraday Soc. 1944, 40, 546-551. [CrossRef] 